\title{
Neutrophil and T Cell Functions in Patients with Congenital Heart Diseases: A Review
}

\author{
Koichi Yuki ${ }^{1,2} \cdot$ Sophia Koutsogiannaki ${ }^{1,2}$
}

Received: 27 March 2021 / Accepted: 14 July 2021 / Published online: 20 July 2021

(C) The Author(s), under exclusive licence to Springer Science+Business Media, LLC, part of Springer Nature 2021

\begin{abstract}
With a significant improvement of survival in patients with congenital heart disease, we expect to encounter these patients more frequently for various medical issues. Clinical studies indicate that infection can pose higher risk in this cohort than general population. Here, with the hypothesis that more severe infection-related complications in CHD cohort may be linked to their inadequate immune response, we reviewed the current literature regarding neutrophil and $\mathrm{T}$ cell functions in patients with congenital heart diseases.
\end{abstract}

Keywords Congenital heart disease $\cdot$ Neutrophil $\cdot$ T cell

\section{Introduction}

A significant improvement of medical and surgical care has transformed life trajectories of patients with congenital heart disease (CHD) over the past decades [1-3]. Because CHD is the most common live birth anomaly with the incidence of 4-10/1000 [4-6] and associated with a better survival, we expect to encounter children with CHD for non-cardiac-related issues more frequently. As seen in the current COVID-19 pandemic [7], infection remains to be one of major public health problems.

Children with CHD are at higher risk of complications associated with cardiac-related infection such as myocarditis and endocarditis, which include hospitalization, intensive care unit admission, mechanical ventilation, longer postoperative hospital stay, and mortality [8-10]. Furthermore, the recent study by Diller et al. demonstrated that in viral pneumonia severe enough to require hospital admission, the need for mechanical ventilation, and the risk of death in patients with CHD significantly increased early in their life compared to the non-CHD cohort, reaching a level equivalent

Koichi Yuki

koichi.yuki@childrens.harvard.edu

1 Department of Anesthesiology, Critical Care and Pain Medicine, Cardiac Anesthesia Division, Boston Children's Hospital, 300 Longwood Avenue, Boston, MA 02115, USA

2 Department of Anaesthesia and Immunology, Harvard Medical School, Boston, MA, USA to non-CHD individuals $>60$ years of age [11]. The relative risk of adverse events (mechanical ventilation, transplantation, extracorporeal lung support, mechanical circulatory support, and death) was 3.5- to 6-fold higher compared with their non-CHD peers, with complex CHDs being particularly at a risk for adverse events. Thus, understanding the underlying mechanism of infection susceptibility in CHD cohort will be important to take better care of this population.

A number of leukocytes are involved in eradicating invading microbes. Among them, neutrophils are the first-line innate immune cells recruited to the site of infection for host defense. Neutrophils target microbes nonspecifically. In contrast, acquired immune cells such as T cells are involved in target-specific immune defense against microbes. The interaction with antigen-presenting cells leads to the expansion of antigen-specific $\mathrm{T}$ cell population for this purpose. Neutrophils and T cells also crosstalk and function complementarily in the setting of infection [12]. More severe infection-related complications in CHD cohort may be linked to their inadequate immune response. Certainly, immune cells other than neutrophils and T cells are also involved in microbial infections, but here we focused to review the function of neutrophils and $\mathrm{T}$ cells in patients with CHD, because they represent the first line of defense for the innate and adaptive immunity, respectively. 


\section{Methods}

\section{Database Search}

We searched electronic databases for leukocyte functions and infection in patients with congenital heart diseases: MEDLINE/PubMed until July 12, 2021. We focused to identify studies describing neutrophil and T cell functions in CHD cohort. "Infection," "neutrophils," "phagocytosis," "respiratory burst," "neutrophil extracellular traps," "T cells," "leukocytes," "white blood cells," "thymectomy," "thymus," "congenital heart disease," "CHD," and "cardiac surgery" were chosen for search.

\section{Neutrophils}

Neutrophils are equipped with a number of methods to eradicate microbes; Phagocytosis, respiratory burst, and neutrophil extracellular traps (NETs) formation are major tools for this purpose [13, 14]. Despite the critical nature of neutrophils in host defense, a very few studies have examined neutrophil functions in patients with CHD so far.

CHD can be classified into cyanotic and acyanotic diseases [15]. Parikh et al. compared phagocytosis, bactericidal function, and chemotaxis between cyanotic and acyanotic CHD. They reported that phagocytosis and bactericidal function were significantly reduced in both cyanotic and acyanotic CHD compared to non-CHD control, while neutrophil chemotaxis in CHD cohorts did not differ from that in non-CHD control [16]. Of note, the authors used bacterial live and dead staining to determine the degree of bacterial killing ability but did not examine the mechanism of how bacteria were killed by neutrophils. They included tetralogy of Fallot (TOF), the transposition of great arteries (TGA), and total anomalous pulmonary venous connection (TAPVR) in cyanotic CHD arm and ventricular septal defect (VSD), atrial septal defect (ASD), aortic stenosis, patent ductus arteriosus (PDA), and valvular pulmonary stenosis in acyanotic CHD arm. This study suggested that at least a subset of CHD might have been associated with reduced neutrophil effector functions with less bacterial killing. Neutrophil oxidative burst is one of the important neutrophil functions to eradicate microbes following phagocytosis. In a study by Akinci et al., no difference in neutrophil oxidation was observed between non-CHD and CHD subjects [17]. As CHD, they enrolled patients with complete atrioventricular canal (CAVC) defect. However, CHD patients with Down syndrome, which is one of the most common syndromes associated with CAVC [18], neutrophil oxidation was significantly less than CHD without Down syndrome. There was no difference in the degree of neutrophil oxidation between
CHD and non-CHD subjects among Down syndrome. The gene of cytosolic superoxide dismutase (SOD-1) is located on chromosome 21 . They showed that SOD-1 level significantly increased in patients with Down syndrome, which would explain less neutrophil oxidation. NETs are structures composed of granules and nuclear constituents expelled by activated neutrophils to degrade virulence factors and kill microbes [19]. So far NETs formation in CHD population has not been reported.

Increasingly, gene mutations responsible for congenital heart diseases have been reported [20, 21]. Approximately 400 genes are associated with CHD by estimate [21]. These genes include genes encoding transcription factors, cell signaling, chromatin modifiers, and myofilament/ extracellular matrix proteins. For example, mutations of genes involved in Notch signaling (ADAM17, HES1, HEY2, JAG1 etc.) and Ras/mitogen-activated protein kinase (MAPK) signaling (SOS1, PTPN11, BRAF, etc.) are reported in a range of CHD, and mice with genetic modification of these genes demonstrated cardiac defects [22-27]. Because both Notch signaling and Ras/MAPK signaling are involved in neutrophil functions [28-30], neutrophils in at least a subset of CHD may be affected by these gene mutations.

In addition, the level of oxygen in the environment may affect neutrophil functions. Neutrophils have oxygen sensor. Under hypoxia, neutrophils can increase the activity of hypoxic-inducible factor (HIF), which lead to their phenotypical changes. Hypoxia can inhibit neutrophil apoptosis, enhance degranulation and the release of antimicrobial products, and promote phagocytosis, but reduce reactive oxygen species (ROS) formation and NETs formation [31]. HIFs are heterodimers of one of three major oxygen labile HIF- $\alpha$ subunits (HIF- $1 \alpha$, HIF- $2 \alpha$, or HIF- $3 \alpha$ ) and a constitutive HIF-1 $\beta$ subunit [32]. HIF- $1 \alpha$ and HIF- $2 \alpha$ are most studied. HIF- $1 \alpha$ is active most during short periods $(<24 \mathrm{~h})$ of intense hypoxia $(<0.1 \%$ oxygen). HIF- $2 \alpha$ is active under mild hypoxia $(<5 \%$ oxygen) and plays a major role during chronic hypoxia. McLeod et al. reported that patients with cyanotic CHD demonstrated higher level of neutrophil elastase, one of the enzymes stored in azurophilic granules in neutrophils, compared to patients with acyanotic CHD and controls, suggesting an increased degranulation in cyanotic heart diseases [33]. In addition, Parikh et al. reported that lower arterial oxygenation was associated with less bactericidal activity among patients with cyanotic CHD [16]. This may be in line with the fact that ROS and NETs formation are impaired under hypoxia. These studies did not investigate the role of HIF in neutrophil functions. The function of these HIF members in CHD needs future investigation. 


\section{T Cells}

$\mathrm{T}$ cells are an essential component of host defense in infection. $T$ cells express a receptor with the potential to recognize diverse antigens from pathogens for eradication.

\section{T Cell Development in Patients with CHD}

The thymus is a primary organ to develop and release naïve $\mathrm{T}$ cells into the peripheral lymphoid organs and blood, which possess the capacity to respond to new antigens. The thymus receives $\mathrm{T}$ cell progenitor cells from the bone marrow for $\mathrm{T}$ cell maturation and selection [34]. T progenitor cells start to express $\mathrm{T}$ cell receptor along with CD4 and CD8 molecules and transform themselves from double-negative (DN) $\mathrm{T}$ cells to double-positive (DP) $\mathrm{T}$ cells [35]. DP T cells are usually quite mobile and interact with a number of ligands to undergo positive and negative selection, which leads to the development of single positive (SP) CD4 or CD8 $\mathrm{T}$ cells. These SP T cells are released peripherally as naïve $\mathrm{T}$ cells. During the process, $\mathrm{T}$ cell receptor (TCR) undergoes VDJ rearrangement. The perivascular space in the thymus is progressively replaced by fat over time, and thymic naïve $\mathrm{T}$ cell production declines significantly with age. Historically, the thymus was thought to be nonfunctional by adulthood [36]. However, the thymus has been shown to produce naïve $\mathrm{T}$ cells on a limited basis. Genetic syndromes such as 22q11.2 microdeletion (DiGeorge) syndrome are associated with both cardiac disease and thymic abnormalities resulting in T cell immunodeficiency [37, 38]. Then, how about CHD patients without DiGeorge syndrome?

$\mathrm{T}$ cell receptor excision circles (TRECs) are small circular pieces of DNA that are byproducts of $\mathrm{T}$ cell maturation in the thymus and have been used as a biomarker for $\mathrm{T}$ cell lymphopoiesis [39]. A study by Davey et al. showed that (1) newborns with CHD demonstrated lower TREC levels than the general population and (2) lower TREC levels were associated with more hospitalization for infection in preterm children with CHD [40]. Interestingly, there was no association between TREC level and CHD severity. Notch1 signaling is critical for $\mathrm{T}$ cell maturation and selection in the thymus [41]. Notch 1 mutation has been reported in a number of CHDs including ASD, VSD, double outlet right ventricle, tricuspid atresia, and interrupted aortic arch, basically ranging from a simple CHD to complex CHD [21]. T cell functional analysis and underlying gene mutations in CHD have not been done extensively so far, but this type of studies are warranted in the future.

\section{latrogenic Alternation of T Cell Development in Patients with CHD}

Thymectomy is frequently performed during surgical correction of congenital heart defects for neonates and infants to obtain better visualization of the vasculatures and the heart during surgical procedures. Within a few years after total thymectomy, the composition of the T cell compartment was dramatically affected in a study by Kurobe et al. [42]. T cell number was significantly reduced in comparison to healthy age-matched controls, with naïve $\mathrm{T}$ cell counts being reduced most. This result was also observed in a study by van Gent et al. [43]. When patients underwent partial thymectomy, a significant reduction in peripheral $\mathrm{T}$ cell number may not be appreciated [42]. The short-term effect of thymectomy on $\mathrm{T}$ cell counts has been also studied by a number of other investigators. Overall, lower TREC was reported after thymectomy along with lower peripheral $\mathrm{T}$ cell counts [36, 44-50]. It is important to point out that the status of complete or partial thymectomy should be noted in these studies because it was not explicitly described in some of them [46, 50, 51].

The long-term effects of thymectomy at neonatal and infant period are much less unequivocal. In a study by van Gent et al., T cell compartment in most individuals had a normal composition at 5 years after thymectomy onward [43]. They also reported the presence of thymic tissue regeneration on magnetic resonance imaging (MRI). However, thymic regeneration after thymectomy was not confirmed in other studies. For example, Prelog et al. reported decreased TREC after thymectomy with no residual thymic tissues either on computer tomography (CT), ultrasound, or MRI, with the mean follow duration of 15 years post-thymectomy [6]. Sauce et al. also reported a decline in CD4 and CD8 $\mathrm{T}$ cell numbers up to 22 years after thymectomy [50]. As described above, some genetic syndromes involving the thymus and $\mathrm{T}$ cell maturation/selection can potentially be involved in CHD, and we need to take these underlying genetic components in consideration as well. $\mathrm{T}$ cells can be largely divided into cytotoxic $\mathrm{T}$ cells, helper $\mathrm{T}$ cells, and regulatory $\mathrm{T}$ cells. Once they are released from the thymus into peripheral circulation, they will undergo further differentiation. Inflammation involving in cardiopulmonary bypass and steroid administration during cardiac surgery can potentially have an impact on $\mathrm{T}$ cell functions and the thymus [52]. These are additional domains that need to be studied in the future. 


\section{Summary}

Predisposition to infection in CHD population has been described in clinical studies. However, the underlying mechanisms of this predisposition remain largely unknown. Possible explanations should be associated with their immune functions, but studies examining immune functions in this population have been rather limited. With more extensive understanding of genetic alternation in CHD population, further studies are needed to elucidate the function of immune cells in CHD.

Author Contributions KY/SK: designed and wrote the manuscript.

Funding This work is supported by CHMC Anesthesia Foundation, NIH R21HD099194 (K.Y., S.K.)

\section{Declarations}

Conflict of interest We do not have any conflict of interest.

Research Involving Human and Animal Rights This article does not contain any studies with human participants or animals performed by any of the authors.

Informed Consent Because of the reason described under "Research involving human participants and/or animals," informed consent is not applicable to this article.

\section{References}

1. Gilboa SM, Salemi JL, Nembhard WN, Fixler DE, Correa A (2010) Mortality resulting from congenital heart disease among children and adults in the United States, 1999 to 2006. Circulation 122(22):2254-2263

2. Gillum RF (1994) Epidemiology of congenital heart disease in the United States. Am Heart J 127(4 Pt 1):919-927

3. Boneva RS, Botto LD, Moore CA, Yang Q, Correa A, Erickson JD (2001) Mortality associated with congenital heart defects in the United States: trends and racial disparities, 1979-1997. Circulation 103(19):2376-2381

4. Hoffman JI, Kaplan S (2002) The incidence of congenital heart disease. J Am Coll Cardiol 39(12):1890-1900

5. Mitchell SC, Korones SB, Berendes HW (1971) Congenital heart disease in 56,109 births. Incidence and natural history. Circulation 43(3):323-332

6. Perloff JK, Warnes CA (2001) Challenges posed by adults with repaired congenital heart disease. Circulation 103(21):2637-2643

7. Yuki K, Fujiogi M, Koutsogiannaki S (2020) COVID-19 pathophysiology: a review. Clin Immunol 215:108427

8. Chiu SN, Shao PL, Wang JK, Chen HC, Lin MT, Chang LY et al (2014) Severe bacterial infection in patients with heterotaxy syndrome. J Pediatr 164(1):99-104

9. Spaeder MC, Carson KA, Vricella LA, Alejo DE, Holmes KW (2011) Impact of the viral respiratory season on postoperative outcomes in children undergoing cardiac surgery. Pediatr Cardiol 32(6):801-806

10. Mohsin SS, Haque A, Shaikh AS, Bano S, Hasan BS (2014) Outcome of infants with unrepaired heart disease admitted to the pediatric intensive care unit: single-center developing country perspective. Congenit Heart Dis 9(2):116-121

11. Diller GP, Enders D, Lammers AE, Orwat S, Schmidt R, Radke RM et al (2020) Mortality and morbidity in patients with congenital heart disease hospitalised for viral pneumonia. Heart 107:1069-1076

12. Leliefeld PH, Koenderman L, Pillay J (2015) How neutrophils shape adaptive immune responses. Front Immunol 6:471

13. Manfredi AA, Ramirez GA, Rovere-Querini P, Maugeri N (2018) The neutrophil's choice: phagocytose vs make neutrophil extracellular traps. Front Immunol 9:288

14. Koutsogiannaki S, Schaefers MM, Okuno T, Ohba M, Yokomizo T, Priebe GP et al (2017) From the cover: prolonged exposure to volatile anesthetic isoflurane worsens the outcome of polymicrobial abdominal sepsis. Toxicol Sci 156(2):402-411

15. Yuki K, Casta A, Uezono S (2011) Anesthetic management of noncardiac surgery for patients with single ventricle physiology. J Anesth 25(2):247-256

16. Parikh S, Bharucha B, Kamdar S, Kshirsagar N (1993) Polymorphonuclear leukocyte functions in children with cyanotic and acyanotic congenital heart disease. Indian Pediatr 30(7):883-890

17. Akinci O, Mihci E, Tacoy S, Kardelen F, Keser I, Aslan M (2010) Neutrophil oxidative metabolism in Down syndrome patients with congenital heart defects. Environ Mol Mutagen 51(1):57-63

18. Lee S, Reddington E, Koutsogiannaki S, Hernandez MR, Odegard $\mathrm{KC}$, DiNardo JA et al (2018) Incidence and risk factors for perioperative cardiovascular and respiratory adverse events in pediatric patients with congenital heart disease undergoing noncardiac procedures. Anesth Analg 127(3):724-729

19. Brinkmann V, Reichard U, Goosmann C, Fauler B, Uhlemann Y, Weiss DS et al (2004) Neutrophil extracellular traps kill bacteria. Science 303(5663):1532-1535

20. Cui M, Wang Z, Bassel-Duby R, Olson EN (2018) Genetic and epigenetic regulation of cardiomyocytes in development, regeneration and disease. Development 145(24):171983

21. Williams K, Carson J, Lo C (2019) Genetics of congenital heart disease. Biomolecules 9(12):91-97

22. Jin SC, Homsy J, Zaidi S, Lu Q, Morton S, DePalma SR et al (2017) Contribution of rare inherited and de novo variants in 2,871 congenital heart disease probands. Nat Genet 49(11):1593-1601

23. Lin CJ, Lin CY, Chen CH, Zhou B, Chang CP (2012) Partitioning the heart: mechanisms of cardiac septation and valve development. Development 139(18):3277-3299

24. Prendiville T, Jay PY, Pu WT (2014) Insights into the genetic structure of congenital heart disease from human and murine studies on monogenic disorders. Cold Spring Harb Perspect Med 4(10): 13946

25. Bonachea EM, Zender G, White P, Corsmeier D, Newsom D, Fitzgerald-Butt $S$ et al (2014) Use of a targeted, combinatorial next-generation sequencing approach for the study of bicuspid aortic valve. BMC Med Genomics 7:56

26. Priest JR, Osoegawa K, Mohammed N, Nanda V, Kundu R, Schultz K et al (2016) De novo and rare variants at multiple loci support the oligogenic origins of atrioventricular septal heart defects. PLoS Genet 12(4):e1005963

27. Lalani SR, Belmont JW (2014) Genetic basis of congenital cardiovascular malformations. Eur J Med Genet 57(8):402-413

28. Shang Y, Smith S, Hu X (2016) Role of Notch signaling in regulating innate immunity and inflammation in health and disease. Protein Cell 7(3):159-174 
29. Kim D, Haynes CL (2013) The role of p38 MAPK in neutrophil functions: single cell chemotaxis and surface marker expression. Analyst 138(22):6826-6833

30. Worthen GS, Avdi N, Buhl AM, Suzuki N, Johnson GL (1994) FMLP activates Ras and Raf in human neutrophils Potential role in activation of MAP kinase. J Clin Invest 94(2):815-823

31. Lodge KM, Thompson AA, Chilvers ER, Condliffe AM (2017) Hypoxic regulation of neutrophil function and consequences for Staphylococcus aureus infection. Microbes Infect 19(3):166-176

32. Koh MY, Powis G (2012) Passing the baton: the HIF switch. Trends Biochem Sci 37(9):364-372

33. McLeod KA, Martin P, Williams G, Walker DR (1994) Neutrophil activation and morbidity in young adults with cyanotic congenital heart disease. Blood Coagul Fibrinol 5(1):17-22

34. Carpenter AC, Bosselut R (2010) Decision checkpoints in the thymus. Nat Immunol 11(8):666-673

35. Takahama Y (2006) Journey through the thymus: stromal guides for T-cell development and selection. Nat Rev Immunol 6(2):127-135

36. Halnon NJ, Jamieson B, Plunkett M, Kitchen CM, Pham T, Krogstad P (2005) Thymic function and impaired maintenance of peripheral $\mathrm{T}$ cell populations in children with congenital heart disease and surgical thymectomy. Pediatr Res 57(1):42-48

37. McLean-Tooke A, Spickett GP, Gennery AR (2007) Immunodeficiency and autoimmunity in 22q11.2 deletion syndrome. Scand J Immunol 66(1):1-7

38. Sullivan KE (2004) The clinical, immunological, and molecular spectrum of chromosome 22q112 deletion syndrome and DiGeorge syndrome. Curr Opin Allergy Clin Immunol 4(6):505-512

39. Livak F, Schatz DG (1996) T-cell receptor alpha locus V(D) $\mathrm{J}$ recombination by-products are abundant in thymocytes and mature T cells. Mol Cell Biol 16(2):609-618

40. Davey BT, Elder RW, Cloutier MM, Bennett N, Lee JH, Wang $\mathrm{Z}$ et al (2019) T-cell receptor excision circles in newborns with congenital heart disease. J Pediatr 213:96-102

41. Huang EY, Gallegos AM, Richards SM, Lehar SM, Bevan MJ (2003) Surface expression of Notch1 on thymocytes: correlation with the double-negative to double-positive transition. J Immunol 171(5):2296-2304

42. Kurobe H, Tominaga T, Sugano M, Hayabuchi Y, Egawa Y, Takahama $\mathrm{Y}$ et al (2013) Complete but not partial thymectomy in early infancy reduces T-cell-mediated immune response: three-year tracing study after pediatric cardiac surgery. J Thorac Cardiovasc Surg 145(3):656-662
43. van Gent R, Schadenberg AW, Otto SA, Nievelstein RA, Sieswerda GT, Haas F et al (2011) Long-term restoration of the human T-cell compartment after thymectomy during infancy: a role for thymic regeneration? Blood 118(3):627-634

44. Brearley S, Gentle TA, Baynham MI, Roberts KD, Abrams LD, Thompson RA (1987) Immunodeficiency following neonatal thymectomy in man. Clin Exp Immunol 70(2):322-327

45. Wells WJ, Parkman R, Smogorzewska E, Barr M (1998) Neonatal thymectomy: does it affect immune function? J Thorac Cardiovasc Surg 115(5):1041-1046

46. Eysteinsdottir JH, Freysdottir J, Haraldsson A, Stefansdottir J, Skaftadottir I, Helgason H et al (2004) The influence of partial or total thymectomy during open heart surgery in infants on the immune function later in life. Clin Exp Immunol 136(2):349-355

47. Madhok AB, Chandrasekran A, Parnell V, Gandhi M, Chowdhury D, Pahwa S (2005) Levels of recent thymic emigrant cells decrease in children undergoing partial thymectomy during cardiac surgery. Clin Diagn Lab Immunol 12(5):563-565

48. Eysteinsdottir JH, Freysdottir J, Skaftadottir I, Helgason H, Haraldsson A, Ogmundsdottir HM (2009) Vbeta usage and T regulatory cells in children following partial or total thymectomy after open heart surgery in infancy. Scand J Immunol 69(2):162-168

49. Prelog M, Keller M, Geiger R, Brandstatter A, Wurzner R, Schweigmann U et al (2009) Thymectomy in early childhood: significant alterations of the CD4(+)CD45RA(+)CD62L(+) T cell compartment in later life. Clin Immunol 130(2):123-132

50. Sauce D, Larsen M, Fastenackels S, Duperrier A, Keller M, Grubeck-Loebenstein B et al (2009) Evidence of premature immune aging in patients thymectomized during early childhood. J Clin Invest 119(10):3070-3078

51. Roosen J, Oosterlinck W, Meyns B (2015) Routine thymectomy in congenital cardiac surgery changes adaptive immunity without clinical relevance. Interact Cardiovasc Thorac Surg 20(1):101-106

52. Whiting D, Yuki K, DiNardo JA (2015) Cardiopulmonary bypass in the pediatric population. Best Pract Res Clin Anaesthesiol 29(2):241-256

Publisher's Note Springer Nature remains neutral with regard to jurisdictional claims in published maps and institutional affiliations. 